\title{
Cardiac, cerebral, renal, optic nerve, and lung ultrasound study (CCROSS) protocol
}

\author{
Protocolo ultrasonográfico enfocado en cirugía cardiaca posquirúrgica CCROSS (cardiac, \\ cerebral, renal, optic nerve, lung ultrasound study)
}

Jessica Garduño-López*, Edgar García-Cruz, and Francisco M. Baranda-Tovar

Cardiovascular Intensive Therapy Unit. Instituto Nacional de Cardiología Ignacio Chávez, Mexico City, Mexico

\begin{abstract}
The use of echocardiography is very useful in the evaluation, treatment, and follow-up of the patient in critical condition. Along with clinic and the stethoscope, it is a tool that complements the act of the physician faced with the diversity of etiologies that determine the state of shock and increase morbidity and mortality, especially in post-cardiac surgery patients, in whom there are no management emergency post-surgical algorithms. In view of this situation, at the National Institute of Cardiology Ignacio Chávez, a management algorithm has been made and improved in cardiac post-surgical patients: through focused ultrasonography, including transthoracic echography, pulmonary ultrasound, optic nerve ultrasound, and renal ultrasound by evaluating renal resistive indices. Several societies have created their protocols for addressing patients in critical condition, so in the institute, specifically in cardiovascular intensive therapy, has created the cardiac, cerebral, renal, optic nerve, and lung ultrasound study (CCROSS) protocol for the initial approach of these patients, and a study is currently taking place for its validation, reproducibility, and efficacy.
\end{abstract}

Key words: Focused ultrasound. Cardiac surgery. Immediate post-surgical. Intensive care unit. Mexico.

\section{Resumen}

El uso de ecocardiografía enfocada es de gran utilidad en la valoración, tratamiento y seguimiento del paciente en estado crítico. Es, junto con la clínica y el estetoscopio, una herramienta que complementa el actuar del médico ante las diversas etiologías que determinan un estado de choque o aumentan la morbimortalidad, especialmente en pacientes posquirúrgicos de cirugía cardíaca, en quienes no se tiene algoritmos de manejo emergente en el posquirúrgico. Ante tal situación, en el Instituto Nacional de Cardiología Ignacio Chávez se ha realizado y propuesto un algoritmo de manejo en los pacientes posquirúrgicos cardíacos: mediante ultrasonografía enfocada, abarcando ecoscopia transtorácica, ultrasonido pulmonar, ultrasonido del nervio óptico y renal mediante la valoración de índices resistivos renales. Diversas sociedades han creado sus protocolos de abordaje en pacientes en estado crítico, por lo que en el Instituto, específicamente en la terapia intensiva

\section{Correspondence:}

*Jessica Garduño-López

Belisario Domínguez, 1

Col. Sección XVI, Del. Tlalpan

Date of reception: 16-11-2018

Date of acceptance: 10-01-2019

C.P. 14080 , Ciudad de México, Mexico

E-mail: jeck_7_7@ hotmail.com

DOI: 10.24875/ACME.M19000035
Available online: $30-10-2019$ Arch Cardiol Mex (Eng). 2019;89(2):126-137 www.archivoscardiologia.com 2604-7063 @ 2019 Instituto Nacional de Cardiología Ignacio Chávez. Published by Permanyer México SA de CV. This is an open access article under the CC BY-NC-ND license (http://creativecommons.org/licenses/by-nc-nd/4.0/). 
cardiovascular, ha creado el protocolo CCROSS (Cardiac, Cerebral, Renal, Optic nerve, lung ultraSound Study) para el abordaje inicial de estos pacientes y se encuentra en marcha actualmente un estudio para su validación, reproducibilidad y eficacia.

Palabras clave: Ultrasonido enfocado. Cirugía cardíaca. Posquirúrgico inmediato. Unidad de cuidados críticos. México.

\section{Introduction}

Immediate post-operative management in cardiac surgery should be carried out in the cardiovascular intensive therapy area and requires a multidisciplinary team with cardiologists and/or doctors specialized in critical medicine with high specialization in cardiovascular intensive therapy, as well as with advanced knowledge of critical echocardiography and critical ultrasonography (pulmonary, vascular accesses, transcranial Doppler, etc.). Early detection of complications deriving from surgery, cardiovascular bypass, and associated comorbidities directly influences on patient prognosis. The use of transthoracic and transesophageal echocardiography helps differential diagnosis in patients with hemodynamic instability, is a safe, lowcost bedside method, and should be available in all cardiovascular intensive care units ${ }^{1}$.

Immediate access to echocardiography $24 \mathrm{~h}$ a day, 7 days a week, is a key to managing the hemodynamic lability that is common after cardiac surgery. Transesophageal echocardiography is essential for diagnosing the cause of hemodynamic instability in ventilated patients after cardiac surgery. An echocardiographic study can support a diagnosis of the left ventricular (LV) failure, hypovolemia, and myocardial ischemia or identify cardiac surgery complications such as tamponade, LV outflow tract dynamic obstruction secondary to anterior mitral valve leaflet systolic movement, or acute right ventricular (RV) failure. Pulmonary echography, simultaneously performed with transthoracic echocardiography (TTE), adds significant diagnostic information that includes identification of pulmonary edema, pleural effusion, consolidation, and pneumothorax ${ }^{2}$.

Due to the above mentioned, cardiovascular intensivist physicians should have basic-advanced training and experience in critical echocardiography (transthoracic and transesophageal) $)^{2,3}$.

\section{Basic concepts}

Homeostasis restoration is one of the primary objectives in cardiac surgery post-operative intensive care, which is affected by changes generated by the use of cardiopulmonary bypass (CPB), as well as by the ischemia-reperfusion phenomenon in the heart, hypothermia, coagulation system disorders, and adverse effects of transfusion therapy due to bleeding ${ }^{4}$.

Clinical assessment should be complemented with focused ultrasonography, following established protocols to determine the primary cause of the state of shock and resolution thereof, as well as possible complications in other organs.

At the Ignacio Chavez National Institute of Cardiology in Mexico City, an ultrasonographic protocol is proposed, focused on post-cardiovascular surgery patients, which aims to detect the etiology of the state of shock and possible complications in the immediate post-operative period, as well as rapid resolution thereof. The algorithm that was developed is based on an adaptation of a specific protocol for patients undergoing cardiac surgery, focused on a sequential analysis for the detection of shock (cardiogenic, hypovolemic, and obstructive), valvulopathies, mobility alterations, prosthetic dysfunction, and non-invasive hemodynamic assessment. On the other hand, it determines compromise of other systems, such as cerebral vascular events of the hemorrhagic or ischemic type secondary to surgical procedures, cardiovascular bypass pump, or anticoagulation, and predicts acute kidney injury (AKI), by means of the renal resistive index (RRI).

It is important for the type of shock and its causes to be determined ${ }^{5}$ :

1. Cardiogenic shock: tissue hypoperfusion, secondary to circulatory collapse due to heart pump failure, myocardial infarction, fulminant myocarditis, post-pericardiotomy syndrome, etc.

2. Hypovolemic shock: with inadequate cardiac preload effect secondary to intravascular loss; for example, post-operative hemorrhage, gastrointestinal hemorrhage, excessive use of diuretics, etc., poor fluid supply

3. Distributive shock: inadequate cardiac preload coexists due to vasodilation and vascular leakage; typical examples are post-pump vasoplegic syndrome, post-operative systemic inflammatory response syndrome, sepsis, and anaphylactic reaction

4. Obstructive shock: inadequate cardiac preload due to venous return obstruction; for example, pericardial tamponade, tension pneumothorax, intra-abdominal 
hypertension, or arterial blood flow obstruction (e.g. pulmonary embolism).

\section{Cardiohemodynamic alterations}

Aortocoronary bypass graft (ACBG) due to the left coronary artery stenosis, triple-vessel disease, and medical treatment-refractory angina is the most common surgical procedure. Other surgical procedures, together with ACBG or alone, include valve repair or replacement, congenital or acquired defects' repair, and aortic root repair or replacement. Less common are intracardiac tumor removal and LV aneurysmectomy ${ }^{6}$.

Worldwide, myocardial revascularization overall mortality is reported to be $3.2 \%$. This appears to be influenced by age, with mortality being $2.6 \%$ in subjects younger than 70 years and $6 \%$ in those older than 70 years. Mortality in valvular surgery is even higher, ranging from 5 to $9 \%$. However, mortality in patients with mitral valve change due to ischemia is $30 \%$.

Myocardial dysfunction is a consequence of ischemia or perioperative infarction, and it requires specific interventions and possible revascularization. It affects $5 \%$ of stable patients and $10 \%$ of unstable subjects, with a mortality of $10 \%{ }^{7,8}$.

\section{Mediastinal bleeding}

It is a complication that occurs in $5-25 \%$ of patients, of which $2-4 \%$ are reoperated ${ }^{9,10}$. Among the causes of low output, suture lines or surgical arterial active bleeding should be ruled out. If bleeding is $>10 \mathrm{~mL} / \mathrm{kg}$ within the $1^{\text {st }} \mathrm{h}, 8 \mathrm{~mL} / \mathrm{kg}$ in the $2^{\text {nd }} \mathrm{h}, 6 \mathrm{~mL} / \mathrm{kg}$ in the $3^{\text {rd }} \mathrm{h}$, or if it adds up to more than $20 \mathrm{~mL} / \mathrm{kg}$ within the first $4 \mathrm{~h}$ or if a sudden increase in the amount of bleeding occurs, it meets the reoperation criteria ${ }^{9,10}$. Christensen defines as severe post-surgical bleeding which is $>200 \mathrm{~mL} / \mathrm{h}-1500 \mathrm{~mL}$ within the first $8 \mathrm{~h}^{11}$.

Another alternative definition considers bleeding $>400 \mathrm{~mL}$ within the $1^{\text {st }}$ hour, $300 \mathrm{~mL}$ within the first $2 \mathrm{~h}$, and $200 \mathrm{~mL}$ for 3 consecutive hours ${ }^{12}$.

In addition, another panel of experts defines severe post-surgical bleeding as blood loss $>1001-2000 \mathrm{~mL} / \mathrm{h}$ through the endopleural tube within the first $12 \mathrm{~h}$ or transfusion of 5-10 units of packed red cells or fresh frozen plasma ${ }^{13}$.

\section{Cardiac tamponade}

It should be suspected in the context of post-operative low cardiac output (CO). It may result from a relatively reduced posterior pericardial fluid collection with associated compression of an adjacent cardiac chamber or a localized chamber. In the early post-operative period, pericardial collections are usually of undrained blood or clots. The diagnosis can be complicated since classic signs, such as pulsus paradoxus, are often absent; according to literature, its incidence is $1.9 \%$. Posterior fluid collection can be found in $66 \%$ of cases and diffuse collection in $34 \%$ of patients. The right atrium collapse occurs in $34 \%$, RV collapse in $27 \%$, and LV diastolic collapse is present in up to $65 \%$ of cases. The most common finding is decreased mitral and aortic diastolic flow during inspiration ${ }^{10}$. Central venous pressure does not have to be elevated, although in the presence of central venous pressure increases versus hypotension and low $\mathrm{CO}$ with progressive increase in vasopressors and inotropic, tamponade should be suspected. Pericardial fluid accumulation suspicion is also justified when thoracic tube drainage abruptly ceases, a situation we are faced with in post-surgical patients. Emergency echocardiography can be useful, although TTE sensitivity is poor, and even a "normal" transthoracic echocardiogram cannot exclude tamponade, and transesophageal echocardiogram is, therefore, indicated ${ }^{14,15}$. However, physical examination and hemodynamic behavior are the main keys to suspect this pathology.

\section{LV failure}

It may be due to transient dysfunction ("stunning") as a result of prolonged CPB pump time and aortic crossclamp times, coronary malperfusion, valvular pathology, and afterload or preload changes. Instruments such as echocardiography can help assess volume status and also identify segmental wall abnormalities consistent with ischemia and valve stenosis or insufficiency. Preload and afterload optimization are essential. Coronary angiography or surgical reintervention may be indicated for revascularization. If these measures fail to restore adequate perfusion, mechanical circulatory support should be considered ${ }^{15,16}$.

\section{RV failure}

It can be caused by post-bypass stunning, coronary malperfusion, or LV failure. The RV is susceptible to afterload and preload acute changes, and a sudden increase in either one of them can precipitate RV acute failure. Pulmonary artery flotation catheter and transthoracic echocardiogram are extremely useful for assessing the RV function ${ }^{15,17}$. 


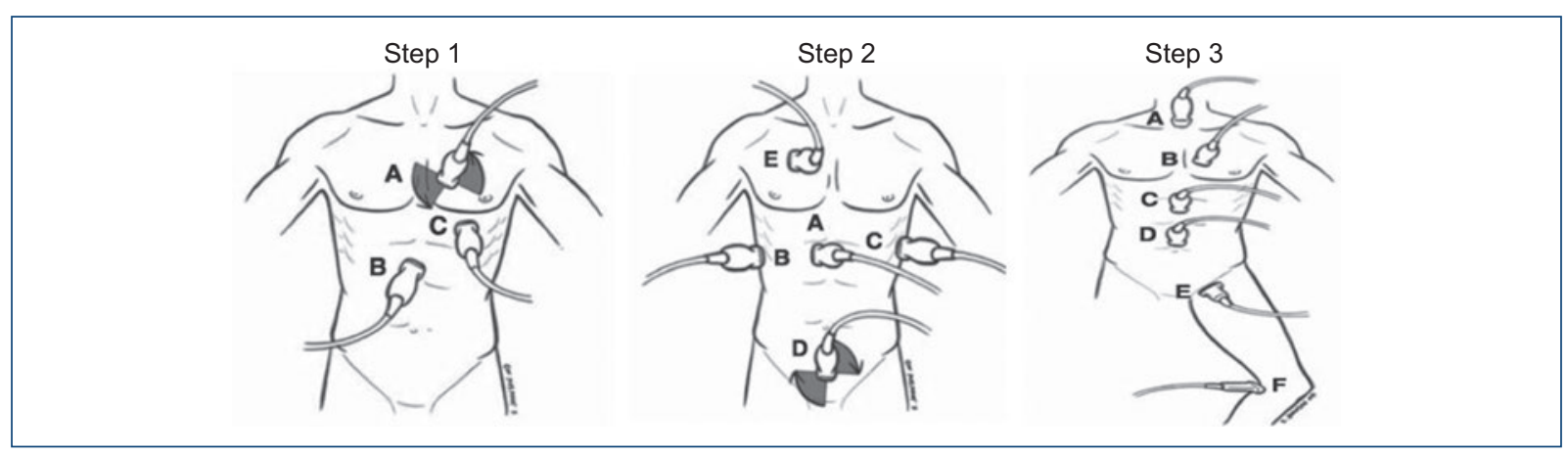

Figure 1. Rapid ultrasound in shock (RUSH). Step 1, "pump” assessment: parasternal view short/long axis (A), subxiphoid view (B), apical view (C). Step 2, "tank" assessment: IVC long axis (A), FAST pleural view (B), FAST pleural view (C), pelvis/FAST (D), pulmonary edema, pneumothorax (E). Step 3, assessment of the "pipes:" suprasternal aorta (A), parasternal aorta (B), epigastric aorta (C), supraumbilical aorta (D), femoral (E), popliteal (F) (adapted from Perera et al., 201027).

\section{Post-cardiotomy shock}

It is defined as a cardiac index $<2.2 \mathrm{~L} / \mathrm{min} / \mathrm{m}^{2}$, with adequate preload. It can be secondary to the LV and/ or RV failure and may or may not be associated with pulmonary congestion. Blood pressure is normal or low, with a clinical presentation consistent with low CO: oliguria (diuresis lower than $0.5 \mathrm{~mL} / \mathrm{kg} / \mathrm{h}$ ), central venous saturation $<60 \%$ (with normal arterial saturation), and $/$ or lactate $>3 \mathrm{mmol} / \mathrm{L}$, without hypovolemia. It has an incidence of $8-10 \%$ with a mortality of up to $70 \%$. Its differential diagnosis is reheating, extreme anemia, allergic reaction, pharmacological effect, hyperacute sepsis, adrenal insufficiency, hyperthyroidism, or pancreatitis. It is characterized by a decrease in endogenous vasopressin concentrations. Its management includes preload optimization and the use of vasopressors such as norepinephrine and vasopressin ${ }^{15,18}$.

Cardiac surgery has been shown to increase the metabolic state, which causes an imbalance between supply and demand, especially in the presence of cardiac dysfunction and limited cardiovascular reserve. Post-surgical cardiovascular support has the purpose to minimize any systemic or local alteration between oxygen supply and consumption $\left(\mathrm{VO}_{2}\right)$. An increase in $\mathrm{VO}_{2}$ between 10 and $20 \%$ occurs in the $1^{\text {st }} \mathrm{h}$ after surgery and is maintained until $48 \mathrm{~h}$, especially in patients with ventilatory mechanical support, pain, anxiety, and delirium ${ }^{1,19}$.

\section{Pulmonary alterations}

Respiratory complications are common in the post-surgical period of patients that have undergone

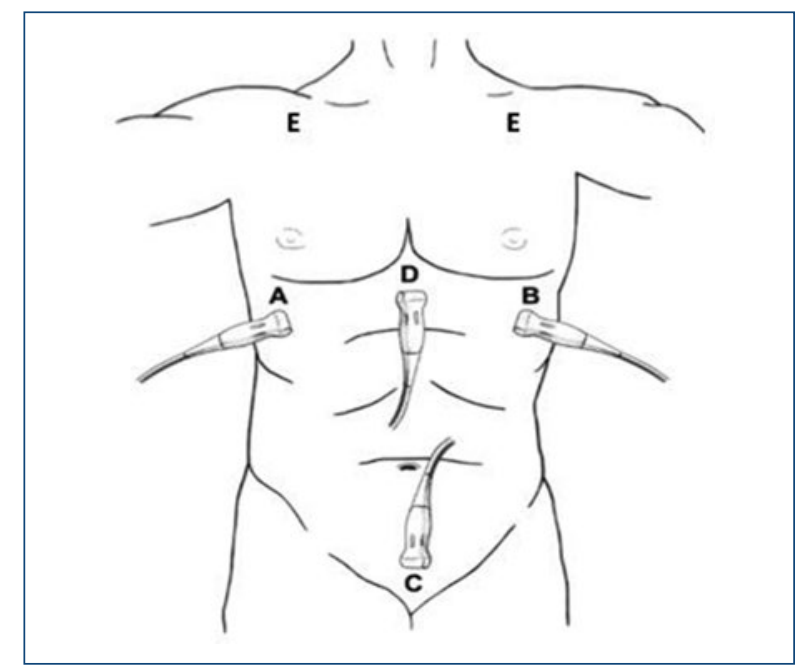

Figure 2. The four views of the focused assessment with sonography for trauma scan. A: upper right quadrant. B: upper left quadrant. C: suprapubic view. D: subxiphoid view of the heart (adapted from Giraldo-Restrepo et al., $\left.2015^{32}\right)$. eFAST: extended to pulmonary apices.

cardiac surgery and can be a consequence of inflammatory factors secondary to CPB, mechanical, and hemodynamic factors (cardiogenic pulmonary edema due to LV failure, mitral residual valvulopathy, stenosis, or insufficiency) ${ }^{20}$.

Post-surgical changes in the pulmonary function are related to multiple factors: general anesthesia, neuromuscular relaxation, sternotomy and mediastinal and pleural drainage, pulmonary edema due to hemodilution, fluid overload and decreased oncotic pressure, interstitial edema caused by systemic inflammatory response, lung damage caused by 


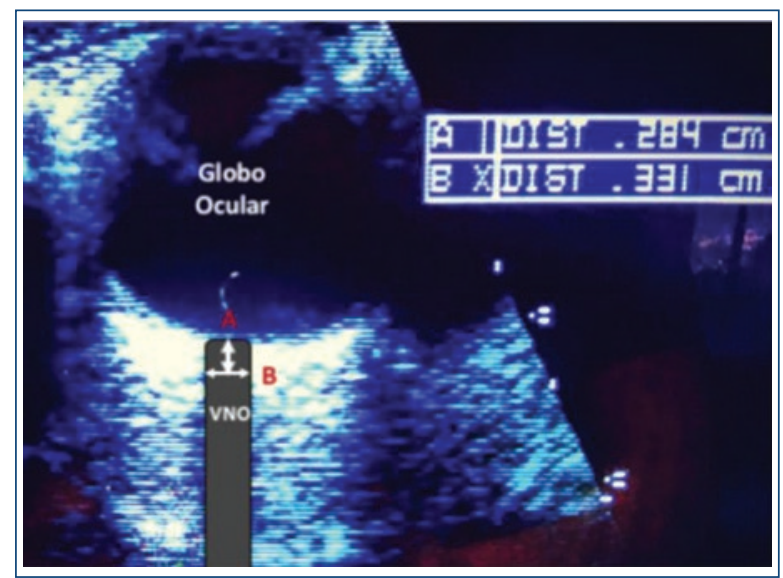

Figure 3. Optic nerve sheath (ONS). A: vertical reference line from the junction of the optic nerve with the eyeball at $3 \mathrm{~mm}$. B:ONS perpendicular cross-section. Globo-ocular. eye globe; VNO: ONS.

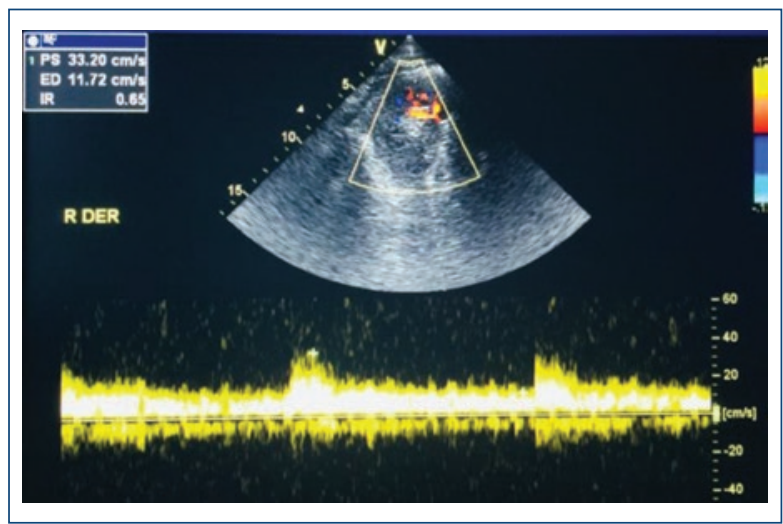

Figure 4. Blood flow curve obtained by Doppler ultrasonography. At the upper part of the figure, interlobar and arcuate arteries flow pattern.

transfusions or by ventricular dysfunction, and hemodynamic compromise ${ }^{15,20}$.

Pulmonary dysfunction due to inflammatory response is well tolerated by most patients and is manifested by a decrease in $\mathrm{PaO}_{2} / \mathrm{FiO}_{2}$ and alveolar compliance and an increase in total pulmonary water. Patients who develop acute lung injury benefit from alveolar protection measures and, given the case, from alveolar recruitment measures to reduce complications secondary to mechanical ventilation-associated lung injury ${ }^{21,22}$.

It is also common for pleural effusions to appear, which should not be punctured unless they cause respiratory impairment or pleural effusions $>50 \%^{23}$.
Table 1. Risk factors for early and late CVA after cardiovascular surgery

\section{Early or intraoperative CVA}

- Peripheral vascular and carotid disease

- Previous cardiac surgery

- Deteriorated initial clinical condition

- Left ventricular dysfunction

- Circumflex stenosis $>70 \%$

- Coronary artery bypass surgery with arrested heart

- Coronary artery bypass surgery with hypothermia and circulatory arrest

- Pre-operative creatinine elevation

- Aortic atherosclerosis

- Longer time on cardiopulmonary bypass

- Advanced age

\author{
Late or post-operative CVA \\ - Main left stenosis \\ - Diabetes \\ - Decreased use of thoracic artery \\ - Female gender \\ - Unstable angina \\ - Post-operative atrial fibrillation \\ - Inotropic support \\ Both early and late CVA \\ - Advanced age \\ - Low body surface area \\ - Pre-operative atrial fibrillation \\ - Old CVA \\ - Coronary artery bypass with hypothermia and circulatory \\ arrest
}

CVA: cerebrovascular accident.

The development of post-surgical atelectasis is etiologically multifactorial ${ }^{24,25}$ :

- Left lower lobe compression in the left mammary artery dissection

- Left phrenic paralysis, which occurs in $2.1 \%$ of patients receiving topical hypothermia with consequent mechanical dysfunction

- Residual atelectasis after collapse when discontinuing mechanical ventilation during CPB

- Alveolar surfactant decrease. The predisposition to atelectasis is increased in the post-operative period due to the presence of pain and the drainage tubes.

Pulmonary thromboembolism occurs in $3.2 \%$ of patients, almost exclusively in those who undergo revascularization, with a mortality rate of $19 \%{ }^{24,25}$.

Therefore, the etiology of respiratory alterations should be assessed, both clinically and with the use of focused pulmonary ultrasound, supported by the international evidence-based consensus on lung focused ultrasonography, published by Volpicelli ${ }^{26}$. 


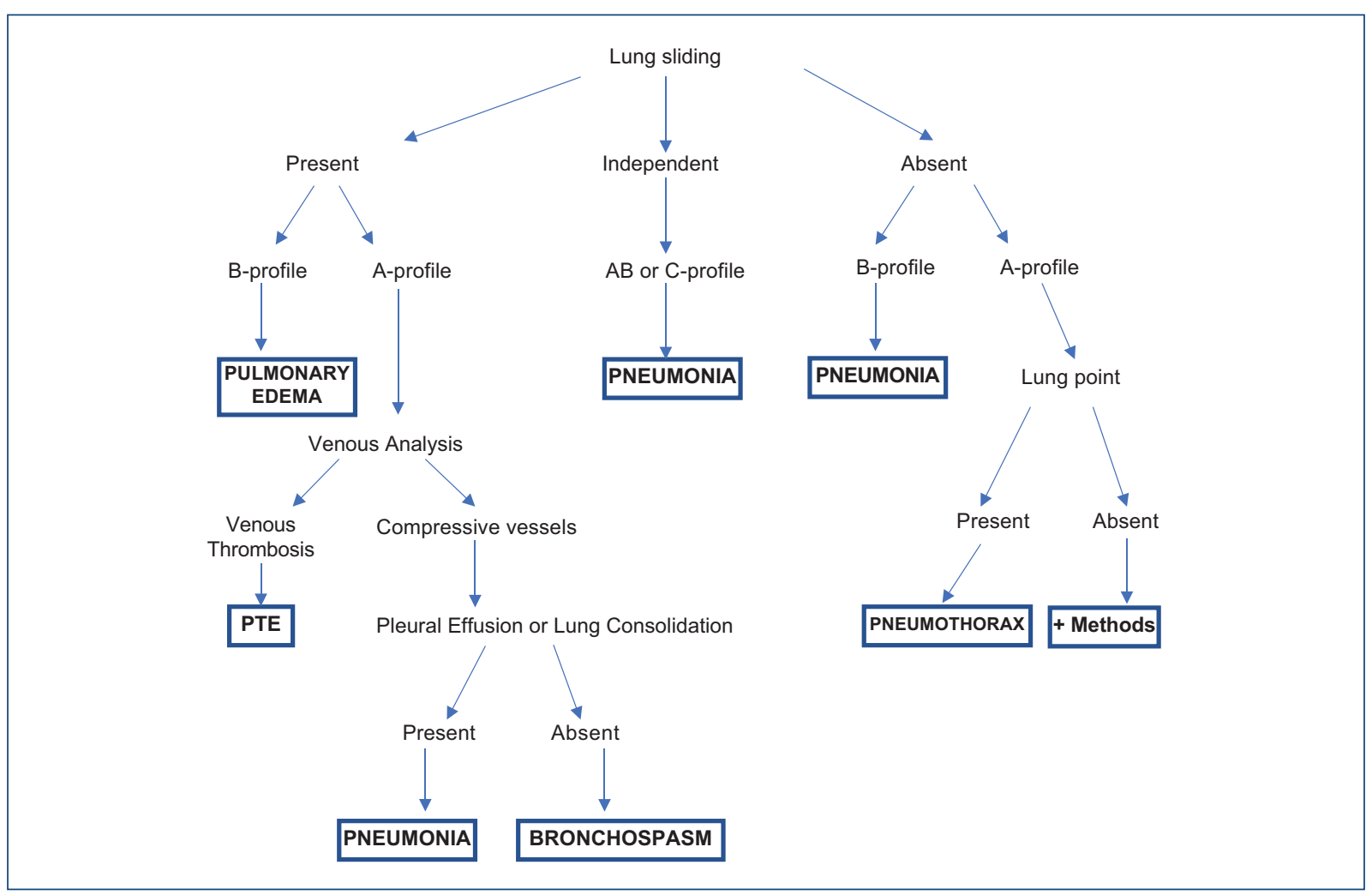

Figure 5. BLUE protocol. Algorithm to assess acute respiratory failure according to pulmonary ultrasound patterns. A-profile: it exhibits lung sliding and A-lines. AB-profile: B-profile, lung sliding in association with B-lines. B-profile: presence of B-lines, lung semi-sliding. C-profile: presence of lung consolidations or areas of atelectasis, associated or not with pleural effusion (adapted from Lichtenstein, 201499).

\section{Cardiac, cerebral, renal, optic nerve, and lung ultrasound study (CCROSS) protocol}

At Ignacio Chavez National Institute of Cardiology, an ultrasonographic protocol focused on cardiovascular surgery post-operative patients is proposed, with the purpose to detect the state of shock causal etiologies in these patients. It is based on the implementation of protocols described in literature, used in patients in state of shock, including hypovolemic shock; consequences of bleeding due to poor surgical technique or induced coagulopathy, hemothorax, cardiogenic shock; and post-pump or due to coronary circulation incidental compromise, perioperative infarction, obstructive shock, and incidental pneumothorax due to the placement of trans-surgical devices. On the other hand, determining involvement of other systems such as cerebral vascular events of hemorrhagic or ischemic type secondary to surgical procedures, CPB pump, and anticoagulation is also sought, and at the same time, and early, predicting AKI by means of the RRI.

\section{Rapid ultrasound in shock (RUSH) protocol and fluid administration limited by lung sonography (FALLS) protocol}

The RUSH protocol and the FALLS protocol are based on the management of shock of undetermined origin according to observation and thoracic ultrasound findings, through the evaluation of three $\operatorname{steps}^{27}$ (Fig. 1): 1. The "pump" which is how determination of the cardiac function is called, and thus, the first aspect to be assessed is the pericardial space, to determine if the patient has an effusion that compromises the hemodynamic state. Second, the LV is assessed to analyze global contractility and to determine the size and state of contractility in case of cardiogenic shock. Third, the examination focuses on determining the relative size of the LV in comparison with the right ventricle, which is essential to rule out right cavities' compromise and ventricular interdependence 27

2. The "tank" is a concept conferred to intravascular volume condition determination through the inferior 


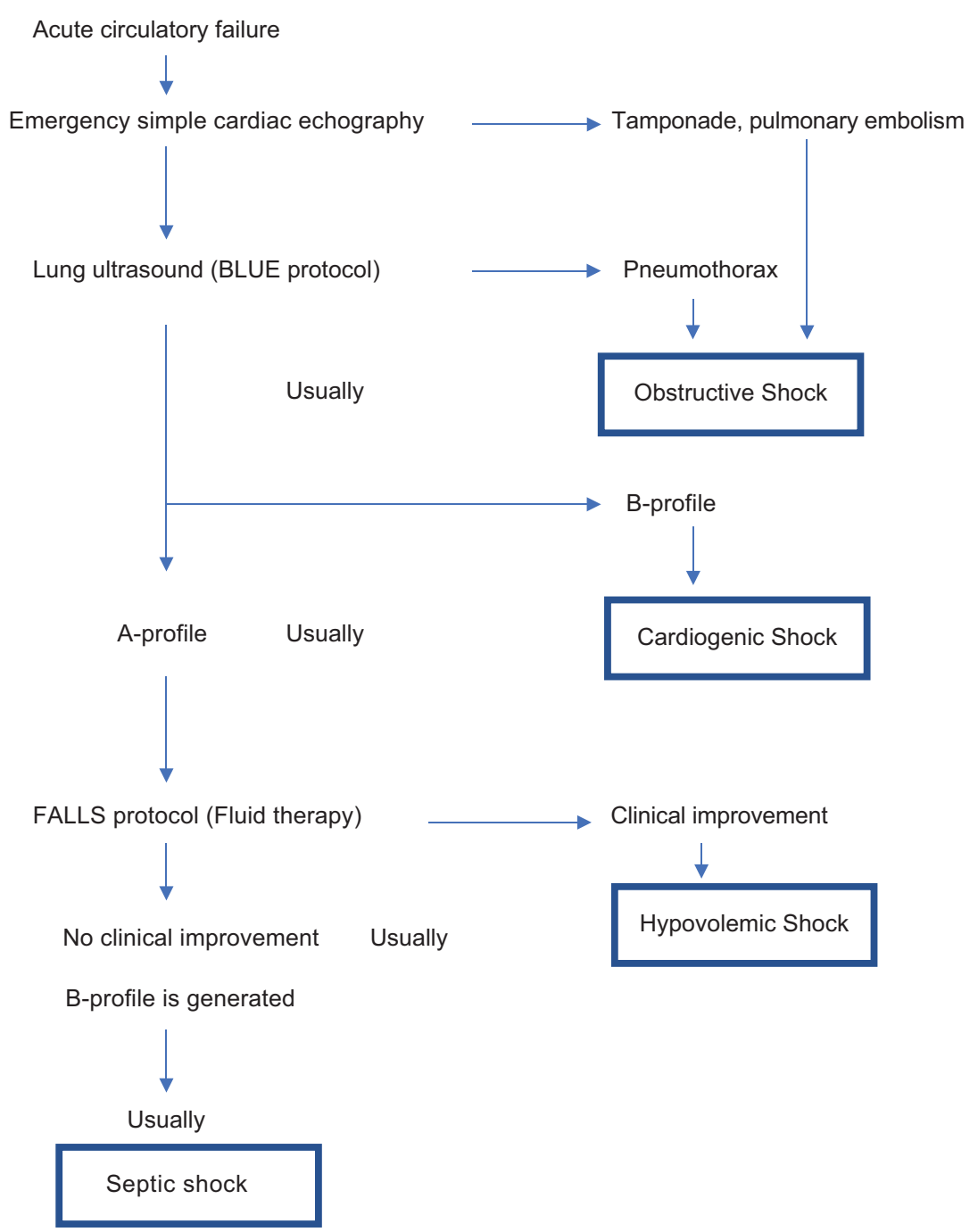

Figure 6. Limited fluid administration by pulmonary ultrasound: the place of pulmonary ultrasound in the assessment of acute circulatory insufficiency (adapted from Lichtenstein, 201230).

vena cava, by means of collapsibility size and index, which leads to suspect hypovolemic shock and response to positive volume ${ }^{27,28}$

3. The "pipes" are the last concept that allows assessing the great arteries and veins of the body, known as the "broken or obstructed pipes," looking for abdominal aneurysm and/or deep venous thrombosis, the latter when there is a lack of total popliteal or femoral venous compression, which in a hypotensive patient also suggests massive pulmonary thromboembolism ${ }^{28}$.

\section{Bedside lung ultrasound in emergency (BLUE) protocol}

The BLUE protocol allows the diagnosis of acute respiratory failure. Pulmonary edema, pulmonary embolism, pneumonia, chronic obstructive pulmonary disease, asthma, and pneumothorax produce specific profiles, which can be suspected of by implementing this protocol $^{29}$ (Fig. 2).

\section{FALLS protocol}

The FALLS protocol adapts the BLUE protocol to acute circulatory failure. It involves sequential search for obstructive, cardiogenic, hypovolemic, and distributive shock by real-time simple echocardiography and then pulmonary ultrasound to assess a direct parameter of clinical volemia: the appearance of $B$-lines, which suggest the presence of interstitial syndrome, is considered as the end point for fluid therapy ${ }^{30,31}$ (Fig. 3). 


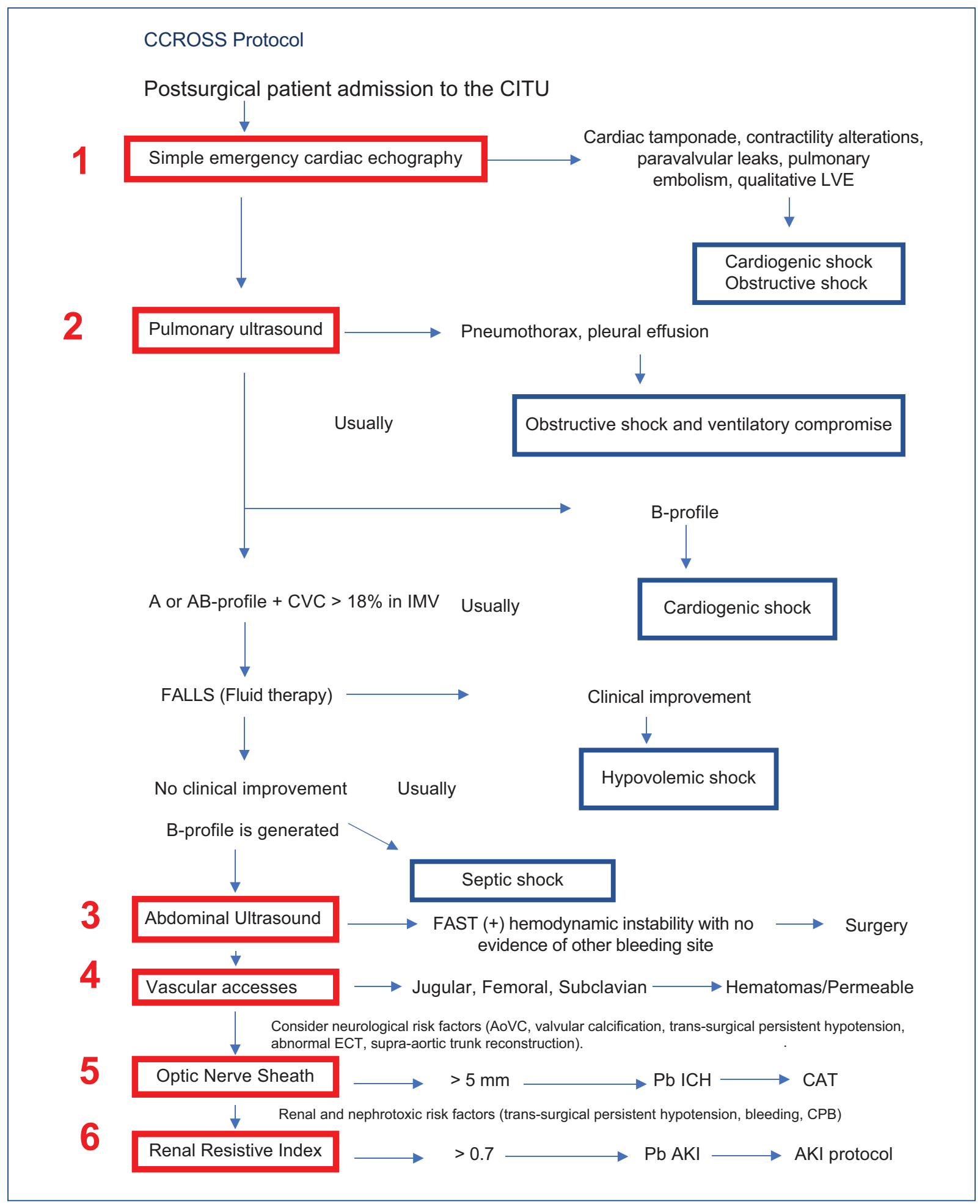

Figure 7. CCROSS protocol Cardiac, cerebral, renal, optic nerve, and lung ultrasound study protocol.

Focused assessment with sonography for trauma (FAST) and extended FAST (eFAST)

FAST and eFAST can help identify free fluid suggestive of hemoperitoneum, hemothorax, hemopericardium, pneumothorax, hemothorax, and atelectasis ${ }^{22-35}$. Its sensitivity varies between 69 and $98 \%$ for the detection of free fluid, and it is $63 \%$ for the detection of solid organ lesion ${ }^{32}$; as for specificity, it is high for the detection of free fluid and solid organs 
Suggested data sheet for ultrasound focused assessment

1

\begin{tabular}{|c|c|c|}
\hline \multicolumn{3}{|l|}{ Heart } \\
\hline Parasternal long axis projection & Yes: & No \\
\hline Aortic annulus diameter (mm) & & \\
\hline Mitral and/or aortic insufficiency (color D.) & & \\
\hline Short axis & & \\
\hline Contractility alterations & & \\
\hline Tricuspid insufficiency and IT velocity $(\mathrm{m} / \mathrm{s})$ & & \\
\hline "Kissing Wall" syndrome & & \\
\hline 4-chamber apical & & \\
\hline Tricuspid insufficiency (severity) & & \\
\hline Tricuspid prosthesis (M or B) leak/gradient & & \\
\hline TTF variability (\%) & & \\
\hline RV diastolic collapse & & \\
\hline RA diastolic collapse & & \\
\hline RV fractional shortening (\%) & & \\
\hline RV lateral S-wave (tissue) & & \\
\hline Cavity dilation (qualitative) & & \\
\hline Qualitative and qualitative LVEF & & \\
\hline $\begin{array}{l}\text { LV mobility alterations } \\
\text { (Affected walls and segments) }\end{array}$ & & \\
\hline Mitral prosthesis (M or B). Leak/gradient & & \\
\hline$E / e^{\prime}(>14)$ & & \\
\hline Diastolic dysfunction (grade) & & \\
\hline FTM variability (\%) & & \\
\hline Mitral insufficiency (severity) & & \\
\hline LVOT VTI $(\mathrm{cm} / \mathrm{s})$ & & \\
\hline LVOT VTI variability (\%) & & \\
\hline Aortic insufficiency & & \\
\hline Aortic prosthesis (M or B). Leak/gradient & & \\
\hline Sub-costal projection & & \\
\hline IVC distensibility (> 18\%) (IMV) & & \\
\hline IVC collapse $(>47 \%)$ (Exp) & & \\
\hline Pericardial effusion (separation $\mathrm{mm}$ ) & & \\
\hline Residual ASD & & \\
\hline Clot anterior to RV & & \\
\hline $\begin{array}{l}\text { Other findings deserving secondary } \\
\text { focused echocardiogram }\end{array}$ & & \\
\hline Stenosis, insufficiency, leaks or severe LVOTO & & \\
\hline Intracavitary masses or thrombi, endocarditis & & \\
\hline $\begin{array}{l}\text { Ventricular assistance (cannulae position, } \\
\text { spontaneous contrast, aortic opening) }\end{array}$ & & \\
\hline
\end{tabular}

2

\begin{tabular}{|c|c|c|}
\hline \multicolumn{3}{|c|}{ Lung } \\
\hline Sliding & Yes & No \\
\hline A-lines & & \\
\hline B-lines & & \\
\hline Bar code & & \\
\hline Pleural effusion & & \\
\hline Static bronchogram & & \\
\hline Dynamic bronchogram & & \\
\hline
\end{tabular}

3

\begin{tabular}{|l|l|l|}
\hline eFAST (anechoic image) & Yes & No \\
\hline Free fluid & & \\
\hline
\end{tabular}

4

\begin{tabular}{|l|l|c|}
\hline \multicolumn{1}{|c|}{ Vascular accesses evaluation } & & \\
\hline Femoral (hematomas/permeable) & Yes & No \\
\hline Jugular (H/P) & & \\
\hline Subclavian (H/P) & & \\
\hline
\end{tabular}

5

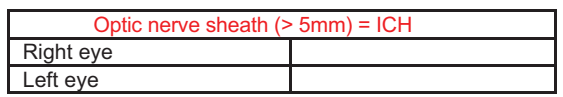

Figure 8. Suggested data sheet for focused ultrasound assessment.

TI: tricuspid insufficiency; M: mechanical; B: biological; TTF: transtricuspid flow; RV: right ventricle; LV: left ventricle; RA: right atrium; LVEF: left ventricular ejection fraction; LVOT VTI: left ventricular outflow tract velocity time integral; IVC: inferior vena cava; ASD: atrial septal defect; LVOTO: left ventricular outflow tract obstruction; H/P: hematoma, permeable.

(94-100\%). eFAST sensitivity for pneumothorax and hemothorax is higher than that of chest radiography (11-21 vs. $43-77 \%)^{32,33}$. The hepatorenal, splenorenal, pelvic, and subxiphoid windows, as well as the pulmonary apices, are assessed $32,33,34$ (Fig. 4).
CCROSS protocol, neurological complications, and optic nerve sheath (ONS) ultrasound measurement

Neurological complications have been an important concern throughout the history of cardiac surgery ${ }^{36}$. 
Neurological complications occur, including ischemic stroke, ischemic hypoxic brain injury, delirium, and cognitive impairment, which entail high morbidity and mortality. On the other hand, intracranial hypertension, as a common complication in patients with acute brain injury, requires early and timely diagnosis and treatment to ensure better evolution ${ }^{37,38}$.

The incidence of post-operative ischemic stroke (predominantly thromboembolic) is up to $4 \%$ for coronary artery bypass graft and may increase to $10 \%$ for valvular replacements and combined procedures and can be further increased with the presence of perioperative atrial fibrillation ${ }^{39}$.

Delirium, often of the hypoactive type, develops in 25$50 \%$ of patients after cardiac surgery and is associated with cognitive impairment and increased mortality ${ }^{40}$.

There are risk factors for early and late stroke after cardiovascular surgery ${ }^{41,42}$ (Table 1).

At present, we have other forms of neurological assessment, which can be performed earlier and are less invasive, such as optic nerve measurement. The optic nerve is a prolongation of the central nervous system and, therefore, it is covered by meninges and cerebrospinal fluid, an anatomical concept that explains the papilledema that occurs with intracranial pressure (ICP) increases and that is the basis of the changes in the ONS diameter, which reflects ICP fluctuations ${ }^{38}$.

The first eye ultrasonography report was made in 1965. In 1997, Hansen and Helmke postulated why the increase in the ONS diameter is closely correlated with ICP increase ${ }^{43}$.

Recently, the measurement of the ONS diameter through the eye window has been proposed as a non-invasive method for the detection of endocranial hypertension, using a high-frequency linear transducer $(7-10 \mathrm{MHz})$. The explanation for this measurement is that the most distal portion of the optic nerve is covered by the dura mater, forming a membrane known as the ONS ${ }^{44}$.

Ultrasonographically, the optic nerve is identified as the hypoechoic structure with a regular course behind the eyeball. Standard measurement requires drawing a vertical line that begins at the junction of the optic nerve with the eyeball; this line is simply a reference and should measure $3 \mathrm{~mm}$. Subsequently, a horizontal line is drawn from border to border of the optic nerve; this second line is the one that measures the optic nerve value in millimeters ${ }^{43,44}$. For most reviewed authors, $5 \mathrm{~mm}$ is the cutoff point for the study to be considered positive for endocranial hypertension ${ }^{45}$ (Fig. 5).

\section{CCROSS protocol and renal complications, and RRI}

Hepatosplenic and renal oxygen extraction are increased by up to $50 \%$ in heart surgery immediate post-surgical period. AKI is one of the most common complications in severely ill patients, which occurs in $30 \%$ of patients in the post-operative period of heart surgery and is associated with high morbidity and mortality ${ }^{46}$.

The risk factors associated with the occurrence of AKI after cardiac surgery includes age, previous arterial hypertension, pre-existing renal lesion, blood transfusion, inotropic support, CPB duration, aortic clamping, hypoxia, and severe hemodilution ${ }^{47}$.

The assessment of AKI is conventionally performed by means of static variables, which are based on late markers of kidney injury such as urinary volume, glomerular filtration, and, even later, creatinine level. The RRI is a marker of AKI early ultrasonographic evaluation characterized for being accessible, reproducible, quantifiable, and dynamic and for having a high sensitivity, specificity, and prognostic capacity ${ }^{48}$.

Anatomically, the right and left renal arteries are direct branches of the abdominal aorta and split at the level of the renal hilum into posterior and anterior; they are divided into segmental arteries and, in turn, into peripherally located interlobar arteries surrounding the renal pyramids, which on reaching the corticomedullary junction, split into arcuate arteries. It is precisely the latter arterial branches where arterial flow velocity is measured. A 2D mode ultrasound technique is used to locate the kidney and color Doppler technique is used to visualize renal irrigation. The corticomedullary renal junction arteries are localized, and using pulsed Doppler, a curve is generated, which has a systolic peak followed by a plateau and finally, the diastolic peak, which generates a characteristic curve ${ }^{49}$ (Fig. 6).

The RRI measured by Doppler ultrasonography was described by Pourcelot with the following formula:

$$
\mathrm{RRI}=\frac{\text { End diastolic velocity }}{\text { Peak systolic velocity }}
$$

$\mathrm{RRI}$ is a useful tool for assessing renal vascular resistance and a range of $0.60-0.70$ is regarded as normal. Serial measurement is recommended ( 3 times) and calculating the average; there should be no variability > $10 \%$ for it to be considered normal and reproducible ${ }^{50}$.

There are other variables that can generate confusion and modify the RRI value. Arterial distensibility 
decrease, increased blood pressure, heart rate, age, intra-abdominal pressure, and the existence of AKI stand out, and special attention should, therefore, be paid to these factors since these are variables that are altered during the post-operative period, including after cardiac surgery procedures ${ }^{51}$.

\section{Conclusions}

This review was carried out with the purpose to lay out the need for the creation of a new ultrasonographic protocol focused on the initial assessment of cardiac surgery post-operative patients, which represent a challenge for the clinician who practices in the cardiovascular intensive therapy field. At present, ultrasound is a highly useful tool for approach and decision-making in patients in critical conditions. Various societies have created their approach protocols and, therefore, the Ignacio Chavez National Institute of Cardiology, specifically in the intensive cardiovascular therapy area, has created the CCROSS protocol for initial approach to these patients and is currently carrying out a study for its validation, reproducibility, and efficacy (Figs. 7 and 8).

\section{Ethical disclosures}

Protection of people and animals. The authors declare that no experiments were performed on humans or animals for this research.

Confidentiality of data. The authors declare that they have followed the protocols of their work center on the publication of patient data.

Right to privacy and informed consent. The authors declare that no patient data appear in this article.

\section{Funding}

The present investigation has not received specific aid from public or commercial sector agencies or non-profit entities.

\section{Conflicts of interest}

The authors declare that they have no conflicts of interest.

\section{References}

1. Aneman A, Brechot N, Brodie D, Colreavy F, Fraser J, Gomersall C, et al. Advances in critical care management of patients undergoing cardiac surgery. Intensive Care Med. 2018;44(6):799-810.
2. Canty DJ, Heiberg J, Tan JA, Yang Y, Royse AG, Royse CF, et al. Assessment of image quality of repeated limited transthoracic echocardiography after cardiac surgery. J Cardiothorac Vasc Anesth. 2017;31:965-72.

3. Rincón Salas JJ. Manejo de las complicaciones postoperatorias de la cirugía cardiaca en cuidados intensivos. Rev Asoc Mex Med Crit y Ter Int. 2013;27(3):172-78.

4. Scott Stephens RS, Whitman GJ. Postoperative critical care of the adult cardiac surgical patient. Part I: Routine postoperative care. Critical Care Medicine. 2015;43(7):1477-97.

5. Kumar A, Parrillo JE. Shock: Classification, pathophysiology, and approach to management. En: Parrillo JE, Dellinger R, editores. Critical care medicine: principles of diagnosis and management in the adult. $3^{\text {rd }}$ ed. Philadelphia: Mosby Elsevier; 2008. pp. 379-422.

6. Melanson P. Managment of post-op cardiac surgery patients [Internet] Montreal, Quebec: McGill University, Critical Care Medicine [mayo de 2001]. Disponible en: https://www.mcgill.ca/criticalcare/teaching/protocols/cardiac.

7. Kahn SS, Denton TA, Czer L. Parrillo J, Dellinger R. Management of the patient after cardiac surgery. Critical Care Medicine: Principles of Diagnostic and management in Adults. $2^{\text {nd }}$ ed. ST Louis: Mosby; 2001. pp. 1-1670.

8. Barado Hualde J. Cuidados postoperatorios en cirugía cardíaca. Med Intensiva. 2002;26:192-3.

9. Vivacqua A, Koch CG, Yousuf AM, Nowicki ER, Houghtaling PL, Blackstone $\mathrm{EH}$, et al. Morbidity of bleeding after cardiac surgery: Is it blood transfusion, reoperation for bleeding, or both? Ann Thorac Surg. 2011;91:1780-90.

10. Navarro OD. Derrame pericárdico y taponamiento cardiaco. Rev Colomb Cardiol. 2017;24(6):622.

11. Christensen MC, Krapf S, Kempel A, von Heymann C. Costs of excessive post operative hemorrhage in cardiac surgery. J Thorac Cardiovasc Surg. 2009;138:687-93.

12. Fergusson DA, Hébert PC, Mazer CD, Fremes S, MacAdams C, Murkin JM, et al.; BART Investigators. A comparison of aprotinin and lysine analogues in high-risk cardiac surgery. N Engl J Med. 2008;358:2319-31.

13. Dyke C, Aronson S, Dietrich W, Hofmann A, Karkouti K, Levi M, et al. Universal definition of perioperative bleeding in adult cardiac surgery. J Thorac Cardiovasc Surg. 2014:147:1458-63.

14. Price S, Prout J, Jaggar SI, Gibson DG, Pepper JR. 'Tamponade' following cardiac surgery: Terminology and echocardiography may both mislead. Eur J Cardiothorac Surg. 2004;26:1156-60.

15. Scott Stephens R. Postoperative critical care of the adult cardiac surgical patient. Part II: Procedure-specific considerations, management of complications, and quality improvement. Crit Care Med. 2015;43:1995-2014.

16. Mebazaa A, Pitsis AA, Rudiger A, et al. Clinical review: Practical recommendations on the management of perioperative heart failure in cardiac surgery. Crit Care 2010;14:201.

17. Itagaki S, Hosseinian L, Varghese R. Right ventricular failure after cardiac surgery: Management strategies. Semin Thorac Cardiovasc Surg. 2012;24:188-94.

18. Hauffe T. Shock management for cardio-surgical ICU patients - The golden hours. Cardiac Failure Review. 2015;1(2):75-82

19. Li P, Qu LP, Qi D, Shen B, Wang YM, Xu JR, et al. Significance of perioperative goal directed hemodynamic approach in preventing postoperative complications in patients after cardiac surgery: a meta analysis and systematic review. Ann Med. 2017;49:343-51.

20. Stephens RS, Shah AS, Whitman GJ. Lung injury and acute respiratory distress syndrome after cardiac surgery. Ann Thorac Surg. 2013;95:1122-29.

21. Ng CS, Wan S, Yim AP, Arifi AA. Pulmonary dysfunction after cardiac surgery. Chest. 2002;121(4):1269-77.

22. Shapira N, Zabatino SM, Ahmed S, Murphy DM, Sullivan D, Lemole GM. Determinants of pulmonary function in patients undergoing coronary bypass operations. Ann Thorac Surg. 1990;50(2):268-73.

23. Johnson D, Hurst T, Thomson D, Mycyk T, Burbridge B, To T, et al. Respiratory function after cardiac surgery. J Cardiothorac Vasc Anesth. 1996:10:571-77.

24. Rousou JA, Parker T, Engelman RM, Breyer RH. Phrenic nerve paresis associated with the use of iced slush and the cooling jacket for topical hypothermia. J Thorac Cardiovasc Surg. 1985;89:921-25.

25. Verheij J, van Lingen A, Raijmakers PG, Spijkstra JJ, Girbes AR, Jansen EK, et al. Pulmonary abnormalities after cardiac surgery are better explained by atelectasis than by increased permeability oedema. Acta Anaesthesiol Scand. 2005;49:1302-10.

26. Volpicelli G. International evidence-based recommendations for point-ofcare lung ultrasound. Intensive Care Med. 2012;38:577-91.

27. Perera P, Mailhot T, Riley D, Mandavia D. The RUSH exam: Rapid Ultrasound in Shock in the evaluation of the critically III. Emerg Med Clin N Am. 2010;28:29-56.

28. Perera P, Mailhot T, Riley D, Mandavia D. The RUSH exam 2012: Rapid Ultrasound in Shock in the evaluation of the critically ill patient. Ultrasound Clin. 2012;7:255-78.

29. Lichtenstein DA. Lung ultrasound in the critically ill. Ann Intensive Care. 2014;4:1.

30. Lichtenstein D, Karakitsos D. Integrating lung ultrasound in the hemodynamic evaluation of acute circulatory failure (the fluid administration limited by lung sonography protocol). J Crit Care. 2012;27:533. 


\section{J. Garduño-López, et al.: Ultrasonographic protocol focused on cardiac surgery post-operative period}

31. Weil MH, Shubin $\mathrm{H}$. Proposed reclassification of shock states with special reference to distributive defects. Adv Exp Med Biol. 1971;23:13-23.

32. Giraldo-Restrepo JA, Serna-Jiménez TJ. The FAST and extended FAST examinations. Col J Anesthesiol. 2015:43(4):299-306.

33. Richards JR, McGahan JP. Focused assessment with sonography in Trauma (FasT) in 2017: What radiologists can learn. Radiology. 2017;283(1):30-48.

34. McGahan JP, Richards J, Gillen M. The focused abdominal sonography for trauma scan. J Ultrasound Med. 2002;21(7):789-800.

35. Galvan DA, Matsushima GK, Frankel HL. Ultrasound in the Surgical Intensive Care Unit. IMAJ. 2011;13:567-70

36. Gilman S. Cerebral disorders after open-heart operations. N Engl J Med. 1965;272:489-98.

37. McDonagh DL. Neurological complications of cardiac surgery. Lance Neurol. 2014;13:490-502.

38. Ropper A. Hiperosmolar therapy for raised intracranial pressure. N Engl J Med. 2012;367:746-52.

39. Nearman H, Klick JC, Eisenberg P, Pesa N. Perioperative complications of cardiac surgery and postoperative care. Crit Care Clin. 2014. 30:527-55.

40. Brown $\mathrm{CH}$. Delirium in the cardiac surgical ICU. Curr Opin Anaesthesiol. 2014;27:117-22

41. Tarakji KG, Sabik JF 3 ${ }^{\text {rd }}$, Bhudia SK, Batizy LH, Blackstone EH. Temporal onset, risk factors, and outcomes associated with stroke after coronary artery bypass grafting. JAMA. 2011;305:381-90.

42. Hedberg M, Boivie P, Engstrom KG. Early and delayed stroke after coronary surgery - an analysis of risk factors and the impact on short- and long-term survival. Eur J Cardiothorac Surg. 2011;40:379-87.
43. Hansen HC, Helmke K. Validation of the optic nerve sheath response to changing cerebrospinal fluid pressure: Ultrasound findings during intrathecal infusion tests. J Neurosurg. 1997;87:34-40.

44. Dubost $C$, Geeraerts T. Possible pitfalls when measuring the optic nerve sheath with sonography. J Surg Res. 2012;2(173):e43-5.

45. Ochoa Pérez L. Aplicaciones de la ultrasonografía en el sistema nervioso central para neuroanestesia y cuidado neurocrítico. Rev Colomb Anestesiol. 2015.

46. Hobson CE, Yavas S, Segal MS, Schold JD, Tribble CG, Layon AJ, Bihorac A. Acute kidney injury is associated with increased longlterm mortality after cardiothoracic surgery. Circulation. 2009;119:2444-53.

47. Wang Y, Bellomo R. Cardiac surgeryaassociated acute kidney injury: risk factors, pathophysiology and treatment. Nat Rev Nephrol. 2017; 13:697-711

48. Carrillo-Esper R, De la Torre-León T, Rosales-Gutiérrez AO, Carrillo-Córdova LD. Indice resistivo renal. Fundamentos e implementación en el enfermo grave. Rev Invest Med Sur Mex. 2014;21(2):68-72.

49. Le Dorze M, Bouglé A, Deruddre S, Duranteau J. Renal Doppler ultrasound: a new tool to assess renal perfusion in critical illness. Shock. 2012;37:360-5.

50. Keogan M, Kliewer M, Hertzberg B, DeLong D, Tupler R, Carroll B. Renal resistive indexes: variability in Doppler US measurement in a healthy population. Radiology. 1996;199:165-9.

51. Wan L, Yang N, Hiew C, Schelleman A, Johnson L, May C, Bellomo R. An assessment of the accuracy of renal blood flow estimation by Doppler ultrasound. Intensive Care Med. 2008;34:1503-10. 